\title{
A Current Landscape of Provincial Perinatal Data Collection in Canada
}

\author{
Kiran A. Massey, BScH, MSc, ${ }^{1-3}$ Laura A. Magee, MD, FRCPC, MSc, FACP, ${ }^{1-6}$ \\ Sheryll Dale, BA, CHIM, ${ }^{5}$ Jennifer Claydon, MSc, ${ }^{7,8}$ Tara J. Morris, BSc, ${ }^{1-3}$ \\ Peter von Dadelszen, MBChB, DPhil, FRCSC, ${ }^{1-5}$ Robert M. Liston, MB, ChB, FRCSC, FRCOG, FACOG, ${ }^{1,3,5}$ \\ J. Mark Ansermino, MBBCh, MSc, FRCPC ${ }^{2,9}$; on behalf of the Canadian Perinatal Network \\ Collaborative Group and the British Columbia Perinatal Health Program* \\ *Members listed in Appendix \\ ${ }^{1}$ Department of Obstetrics and Gynaecology, University of British Columbia, Vancouver BC \\ ${ }^{2}$ Centre for Advanced Health Research and Evaluation, University of British Columbia, Vancouver BC \\ ${ }^{3} \mathrm{BC}$ Women's Hospital and Health Centre, Vancouver BC \\ ${ }^{4}$ Department of Population and Public Health, University of British Columbia, Vancouver BC \\ ${ }^{5}$ British Columbia Perinatal Health Program, Vancouver BC \\ ${ }^{6}$ Department of Medicine, University of British Columbia, Vancouver BC \\ ${ }^{7}$ Department of Paediatrics, University of British Columbia, Vancouver BC \\ ${ }^{8}$ Canadian Perinatal Surgery Network, Vancouver BC \\ ${ }^{9}$ Department of Anesthesiology, Pharmacology and Therapeutics, University of British Columbia, Vancouver BC
}

\section{Abstract}

Background: The Canadian Perinatal Network (CPN) was launched in 2005 as a national perinatal database project designed to identify best practices in maternity care. The inaugural project of $\mathrm{CPN}$ is focused on interventions that optimize maternal and perinatal outcomes in women with threatened preterm birth at $22+0$ to $28+6$ weeks' gestation.

Objective: To examine existing data collection by perinatal health programs (PHPs) to inform decisions about shared data collection and CPN database construction.

Methods: We reviewed the database manuals and websites of all Canadian PHPs and compiled a list of data fields and their definitions. We compared these fields and definitions with those of $\mathrm{CPN}$ and the Canadian Minimal Dataset, proposed as a common dataset by the Canadian Perinatal Programs Coalition of Canadian PHPs.

Results: PHPs collect information on $2 / 3$ of deliveries in Canada. PHPs consistently collect information on maternal demographics (including both maternal and neonatal personal identifiers), past obstetrical history, maternal lifestyle, aspects of labour and delivery, and basic neonatal outcomes. However, most PHPs collect insufficient data to enable identification of obstetric (and neonatal) practices associated with improved maternal and perinatal outcomes. In addition, there is between-PHP variability in defining many data fields.

Key Words: Perinatal database, reproductive care programs, knowledge interaction, electronic health record, Canadian Perinatal Network, perinatal outcomes

Competing Interests: None declared.

Received on August 9, 2008

Accepted on October 8, 2008
Conclusion: Construction of a separate CPN database was needed, although harmonization of data field definitions with those of the proposed Canadian Minimal Dataset was done to plan for future shared data collection. This convergence should be the goal of researchers and clinicians alike as we construct a common language for electronic health records.

\section{Résumé}

Contexte : Le Réseau périnatal canadien (RPC) a été lancé en 2005 en tant que projet national de base de données périnatale conçue pour identifier les pratiques optimales en matière de soins de maternité. Le projet inaugural du RPC est axé sur les interventions qui optimisent les issues maternelles et périnatales chez les femmes qui présentent une menace d'accouchement préterme à $22+0$ à $28+6$ semaines de gestation.

Objectif : Examiner les systèmes existants de collecte de données par des programmes de santé périnatale (PSP) en vue d'éclairer les décisions au sujet de la collecte commune de données et de la construction de la base de données RPC.

Méthodes: Nous avons analysé les sites Web et les manuels de base de données de tous les PSP canadiens, et compilé une liste de champs de données et de leurs définitions. Nous avons comparé ces champs et ces définitions avec ceux du RPC et du Canadian Minimal Dataset, lequel a été proposé en tant qu'ensemble de données commun par le Partenariat des programmes périnatals du Canada des PSP canadiens.

Résultats : Les PSP recueillent des données sur les $2 / 3$ des accouchements au Canada. Les $P S P$ recueillent régulièrement de l'information sur les caractéristiques démographiques maternelles (y compris les identificateurs personnels de la mère et du nouveau-né), les antécédents obstétricaux, le mode de vie maternel, les aspects du travail et de l'accouchement, et les issues néonatales de base. Cependant, la plupart des PSP ne recueillent pas suffisamment de données pour permettre l'identification des pratiques obstétricales (et néonatales) associées à l'amélioration des issues maternelles et périnatales. De plus, on a constaté une variabilité inter-PSP pour ce qui est de la définition de nombreux champs de données. 
Conclusion : La construction d'une base de données RPC distincte s'est avérée requise; cependant, nous avons procédé à I'harmonisation des définitions de champ de données avec celles du Canadian Minimal Dataset proposé de façon à préparer une future mise en commun de la collecte de données. Cette convergence devrait être l'objectif tant des chercheurs que des cliniciens au fur et à mesure que nous bâtissons une langue commune pour ce qui est des dossiers de santé électronique.

J Obstet Gynaecol Can 2009;31(3):236-246

\section{INTRODUCTION}

In Canada, more than 350000 babies are born each year. Preterm birth complicates $7.6 \%$ of births, with variations of $\pm 15 \%$ between provinces. ${ }^{1}$ Despite improvements in prenatal care, preterm birth is still the most important cause of perinatal mortality and morbidity, and it is recognized to hold the greatest potential for improved outcomes. ${ }^{1}$

While it is certain that obstetric practice can influence neonatal outcomes, there are many controversies around the care of women at risk for very preterm delivery. The inaugural project of the Canadian Perinatal Network is to identify, in the context of threatened very preterm births at $22+0$ to $28+6$ weeks' gestation, interventions that are related to good or poor maternal and perinatal outcomes and to greater or lesser resource use. This requires collection of detailed information about obstetric practices, which CPN hopes eventually to collect from all 24 tertiary perinatal units in Canada. CPN also links with the well-established Canadian Neonatal Network and Canadian Perinatal Surgery Network.

Many tertiary perinatal units collect data as part of a provincial perinatal health program. These programs have been set up to monitor geographical disparities in perinatal health and in determinants of adverse outcomes (e.g., low socioeconomic status). Much of this information is used for regional reporting to governments and policy makers; however, this is only a portion of the larger mandate of the PHPs. The mandate also includes peer review, education, and guideline development. We analyzed the breadth of data collection by Canadian PHPs in the hope of harmonizing their data collection with that of CPN. Presented here is

\section{ABBREVIATIONS}

$\begin{array}{ll}\text { APHP } & \text { Alberta Perinatal Health Program } \\ \text { BCPHP } & \text { British Columbia Perinatal Health Program } \\ \text { CMDS } & \text { Canadian Minimal Dataset } \\ \text { CPN } & \text { Canadian Perinatal Network } \\ \text { CPPC } & \text { Canadian Perinatal Programs Coalition } \\ \text { MgSO }_{4} & \text { Magnesium sulfate } \\ \text { Niday } & \text { Niday Perinatal Database (Ontario) } \\ \text { NLPPP } & \text { Newfoundland and Labrador Provincial Perinatal Program } \\ \text { NSAPD } & \text { Nova Scotia Atlee Perinatal Database } \\ \text { PEIRCP Prince Edward Island Reproductive Care Program } \\ \text { PHP } & \text { Perinatal health program }\end{array}$

a detailed analysis of existing data collection by Canadian PHPs.

\section{METHODS}

Information about PHPs was gathered from websites, provincial reports, and one-on-one communication with coordinators. With the assistance of representatives at the BCPHP, we contacted the coordinators from existing PHPs, and then requested and received electronic manuals for their databases. From these manuals, each data field and its definition were recorded to form a master table. This table was sent to the coordinators of each of the provincial PHPs to confirm accuracy of the PHP data collection. This included clarifying which data fields were collected from the medical record and which were obtained from the Canadian Institute for Health Information database, which includes demographics, ICD-10 diagnoses, and procedures.

The information in the table was organized into the following categories: demographics; past medical, obstetric, and surgical history; current pregnancy; maternal complications and interventions; fetal complications and interventions; labour and delivery; and perinatal outcomes.

For the purposes of comparison, our analysis includes data fields and definitions from the Canadian Minimal Dataset proposed by the Canadian Perinatal Programs Coalition ${ }^{2}$ and the CPN Database (May 2008 version). ${ }^{3}$

The Canadian Perinatal Programs Coalition Database Committee was created in 1988 and aims to serve as a vehicle for the exchange of ideas and information between professionals involved in the PHPs. At present, each province with a PHP collects its own data, but the CPPC is in the process of determining how and what could be shared nationally, while still satisfying each province's needs and privacy concerns. The CPPC recognizes both the variability in the information collected and the lack of standardized definitions.

The CPPC has proposed a CMDS, and the provinces are currently comparing their respective databases to the CMDS. Each will make a commitment as to when they will be in compliance with the CMDS. ${ }^{2}$

Although there are a variety of regional databases, for example Southwestern Ontario Perinatal Partnership, we included only provincial perinatal initiatives. It is also important to note that there are other provincial networks, such as the Fetal Alert Network in Ontario, which focus on birth defects and prenatal screening. Quebec, Saskatchewan, Northwest Territories, Nunavut, New Brunswick, and Manitoba were not included because none of them have a functional reproductive care database, although some are in the process of establishing one.

\section{RESULTS}

Since 2004, PHPs have collectively covered two thirds of births in Canada, with perinatal data collection beginning as early as 1988 by the Nova Scotia Atlee Perinatal Database. The six programs used in this analysis (Table 1) are NSAPD ${ }^{4}$ Prince Edward Island Reproductive Care Program, ${ }^{5}$ Newfoundland and Labrador Provincial Perinatal 
Table 1. Canadian perinatal health programs

\begin{tabular}{|c|c|c|c|c|c|c|}
\hline Variables & RCPNS (NS) & PEIRCP (PEI) & NLPPP (NL) & Niday (ON) & APHP (AB) & $\mathrm{BCPHP}(\mathrm{BC})^{*}$ \\
\hline $\begin{array}{l}\text { Program } \\
\text { established }\end{array}$ & 1973 & 1984 & 1979 & 1997 & 1992 & 1988 \\
\hline $\begin{array}{l}\text { Database } \\
\text { established }\end{array}$ & 1988 (NSAPD) & 1990 & 2001 & 1997 & 1992 & 1994 \\
\hline $\begin{array}{l}\text { Version used } \\
\text { in this analysis }\end{array}$ & Apr 2007 & 2007 & Oct 2007 & Nov 2006 & Oct 2007 & Apr 2008 \\
\hline Population & $\begin{array}{l}\text { All pregnanciest } \\
\text { and births in NS }\end{array}$ & All pregnancies $\ddagger \S$ & $\begin{array}{l}\text { All pregnancies } \neq \\
\text { and births in } 2 \\
\text { health authorities } \|\end{array}$ & All births in ONT & All births in $A B$ & All births in $B C$ \\
\hline $\begin{array}{l}\text { Deliveries/yr in } \\
\text { database }\end{array}$ & $8500(2006)$ & $1400(2005)$ & $2800(2002)$ & $125000(2006 / 07)$ & $45200(2006)$ & $42000(2007)$ \\
\hline Website & $\begin{array}{c}\text { http://rcp. } \\
\text { nshealth.ca }\end{array}$ & $\begin{array}{l}\text { http://www.gov. } \\
\text { pe.ca/health }\end{array}$ & $\begin{array}{l}\text { http://www. } \\
\text { nlppp.ca }\end{array}$ & $\begin{array}{l}\text { https://www.niday } \\
\text { database.com }\end{array}$ & http://www.aphp.ca & $\begin{array}{l}\text { http://www. } \\
\text { bcphp.ca }\end{array}$ \\
\hline $\begin{array}{l}\mathrm{ClHI} \text { data } \\
\text { included? }\end{array}$ & Yes & No & Yes & No & No & Yes \\
\hline \multicolumn{7}{|c|}{$\begin{array}{l}\text { RCPNS: Reproductive Care Program of Nova Scotia } \\
\text { *The BC Perinatal Database is also used by Yukon. } \\
\text { tIncludes only pregnancies reported after } 20 \text { weeks gestation. } \\
\text { †Includes babies born to Nova Scotia residents. } \\
\text { §Includes babies born to Prince Edward Island residents. } \\
\text { \|Includes Children's and Women's Health Program of Eastern Health. } \\
\text { शIn 2006/2007, } 95 \% \text { of births in Ontario. }\end{array}$} \\
\hline
\end{tabular}

\section{Table 2. Demographics}

\begin{tabular}{|c|c|c|c|}
\hline Variables & $\begin{array}{l}\text { PHPs that collect } \\
\text { the information } \\
\qquad(\mathrm{N}=6)\end{array}$ & CMDS & CPN \\
\hline $\begin{array}{l}\text { Maternal personal identifiers } \\
\text { (one or more) }\end{array}$ & 6 & $\checkmark$ & $\checkmark$ \\
\hline Hospital chart number & 6 & & $\checkmark$ \\
\hline Provincial health number & $4^{*}$ & $\checkmark$ & $\checkmark$ \\
\hline Mother's first/last name & 3 & & $\checkmark$ \\
\hline Mother's date of birth & 6 & $\checkmark$ & $\checkmark$ \\
\hline Other† & 4 & & $\checkmark$ \\
\hline $\begin{array}{l}\text { Infant(s) personal identifiers } \\
\text { (one or more) }\end{array}$ & 6 & $\checkmark$ & $\checkmark$ \\
\hline Hospital chart number & 5 & $\checkmark$ & $\checkmark$ \\
\hline Provincial health number & 4 & & \\
\hline Infant's first/last name & 3 & & $\checkmark$ \\
\hline Date of birth & 6 & $\checkmark$ & $\checkmark$ \\
\hline Ethnicity & $2 \ddagger$ & & $\sqrt{ } \S$ \\
\hline Language spoken & 1 & & \\
\hline Socioeconomic status $\|$ & 6 & & $\checkmark$ \\
\hline Lone parent & 4 & $\checkmark$ & $\checkmark$ \\
\hline $\begin{array}{l}\text { BMI (calculated from pre- } \\
\text { pregnancy height and weight) }\end{array}$ & 6 & $\checkmark$ & $\checkmark$ \\
\hline \multicolumn{4}{|c|}{$\begin{array}{l}\text { BMI: body mass index. } \\
\text { *Includes NLPPP, PEIRCP, NSAPD, and BCPHP. } \\
\text { †Some programs collect information about street address, city, health } \\
\text { region, province, country of residence (as opposed to place of birth). } \\
\text { †Niday collects information on Aboriginal status (First Nations, Métis, Inuit), } \\
\text { while NSAPD collects non-mandatory information about the following races } \\
\text { or ethnicities: Acadian, African-Canadian, Asian, Caucasian, } \\
\text { First Nations, Hispanic, Jewish, Mediterranean, Middle Eastern, } \\
\text { Québécois, other. } \\
\text { §CPN collects information on broad categories, but the information } \\
\text { is not mandatory. } \\
\text { |Socioeconomic status is defined by education, occupation, and/ } \\
\text { or postal code. }\end{array}$} \\
\hline
\end{tabular}

Program, ${ }^{6}$ Niday Perinatal Database (Ontario), ${ }^{7}$ Alberta Perinatal Health Program, ${ }^{8}$ and British Columbia Perinatal Health Program. ${ }^{9}$ The data from Whitehorse (Yukon) are collected using the BCPHP database platform but are housed in their own separate territorial database.?

Table 2 (demographics) shows that while all programs collect maternal and infant personal identifiers, only two document ethnicity: Niday, in Ontario, which only defines aboriginal status and NSAPD, in which ethnicity is a non-mandatory field, report some form of personal identifier for both mother and baby. Maternal chart number is documented by all PHPs, with the most recent addition being Niday in 2004. Personal health numbers are collected by four PHPs (PEIRCP, NSAPD, NLPPP, and BCPHP), the CMDS, and CPN. All PHPs gather socioeconomic status and body mass index data, while lone parent status is collected by four PHPs. CPN collects most maternal and infant identifiers, ethnicity (not mandatory), and other demographics listed in Table 2.

Table 3 (past medical, obstetric, and surgical history) shows most PHPs document previous diabetes mellitus, miscarriages or terminations, perinatal deaths, or Caesarean sections. While the data fields are similar, many definitions are different. For example, pre-existing hypertension is defined by CPN as "a blood pressure of 140/90 or greater at least twice before pregnancy or before 20 weeks" gestation"3; NSAPD defines pre-existing hypertension as "documentation that would indicate hypertension was a diagnosis or present before pregnancy"4; while NLPPP uses only the ICD-10-CA code (010). Most PHPs that collect parity also differ in the style of collection; PEIRCP and NLPPP 
calculate parity as (gravidity-[elective terminations + miscarriages]). BCPHP records parity as $\geq 1$ if any of previous term + preterm births, previous vaginal deliveries + previous Caesarean deliveries, or living children is greater than 0 . Other PHPs such as NSAPD and CPN calculate parity by totalling the previous number of stillbirths and live births, while APHP collects parity as gravida - abortions-1 (for the current pregnancy). Previous stillbirths are collected by most PHPs and are consistently defined as the complete expulsion or extraction from its mother after at least 20 completed weeks gestation or after attaining a weight of at least $500 \mathrm{~g}$, of a product of conception in which, after the expulsion or extraction, there is no breathing, cardiac activity, pulsation of the umbilical cord, or unmistakable movement of voluntary muscle. The only PHP that uses a different definition of stillbirth is Niday, which defines stillbirth as occurring at greater than 20 weeks, though the Niday system will allow births of 18-20 weeks. Preterm birth is documented by all PHPs, $\mathrm{CPN}$, and the CMDS; however, definitions vary: most include babies born at < 37 weeks' gestation $(\mathrm{CPN}$, PEIRCP, NLPPP, BCPHP), while others such as NSAPD use LMP, ultrasound dating, and infant clinical assessment to define preterm birth (although $<37$ weeks is the most common definition). Few PHPs document other previous medical complications (e.g., gestational diabetes mellitus or gestational hypertension). This pattern of data collection is reflected by CMDS. CPN collects more detailed previous medical and obstetric complications relevant to the major determinant of very preterm birth.

Table 4 (current pregnancy) shows limited reporting on most variables by all programs. All PHPs, CMDS, and CPN collect information regarding expected date of confinement and multiple pregnancies. Although lifestyle choices, such as tobacco, alcohol, and illicit drug use, are documented by all PHPs, they differ in the data fields and the amount of detail they collect. For example, most collect the number of cigarettes per day in pregnancy, but only two PHPs (Niday and PEIRCP) and the CMDS specify whether or not there was smoking before or after 20 weeks. Moreover, only two PHPs (PEIRCP and NLPPP) and the CMDS document exposure to environmental tobacco, and only the CMDS collects nicotine replacement therapy. The same trend applies with alcohol; while all PHPs, the CMDS, and CPN collect alcohol or illicit drug use in the pregnancy, only two PHPs, the CMDS, and CPN collect the amount of alcohol used (e.g., bingeing, or $>3$ drinks/day), while NSAPD collects only alcohol abuse without being any more specific. Only three PHPs, the CMDS, and CPN specify which illicit drugs are used (e.g., opiates, cannabis, cocaine, hallucinogens, stimulants, solvents). Many PHPs collect information on the nature of prenatal care and type of provider, as does
Table 3. Past medical/obstetric/surgical history

\begin{tabular}{|c|c|c|c|}
\hline Variables & $\begin{array}{l}\text { PHPs that } \\
\text { collect the } \\
\text { information } \\
(\mathrm{N}=6)\end{array}$ & CMDS & CPN \\
\hline \multicolumn{4}{|l|}{ Medical history } \\
\hline Pre-existing hypertension & 5 & $\checkmark$ & $\checkmark$ \\
\hline Diabetes mellitus & 5 & $\checkmark$ & $\checkmark$ \\
\hline Thromboembolism & 2 & & $\checkmark$ \\
\hline Thrombophilia & 2 & & $\checkmark$ \\
\hline Other* & 4 & & \\
\hline Previous blood transfusion & 1 & & \\
\hline \multicolumn{4}{|l|}{ Obstetric/gynaecological history } \\
\hline Gravidity & 4 & $\checkmark$ & $\checkmark$ \\
\hline Parity & 5 & $\checkmark$ & $\checkmark$ \\
\hline Reported directly & 1 & & \\
\hline Calculated & 4 & $\checkmark$ & $\checkmark$ \\
\hline Spontaneous abortions & 2 & $\checkmark$ & $\checkmark$ \\
\hline Elective terminations & 2 & $\checkmark$ & $\checkmark$ \\
\hline $\begin{array}{l}\text { Abortions } \\
\text { (spontaneous and therapeutic) }\end{array}$ & 5 & $\checkmark$ & $\checkmark$ \\
\hline Uterine structural abnormalities & 3 & & $\checkmark$ \\
\hline \multicolumn{4}{|l|}{ Prior obstetric history } \\
\hline Previous congenital anomalies & 2 & & \\
\hline Previous stillbirth & 5 & $\checkmark$ & $\checkmark$ \\
\hline Previous neonatal death & 5 & $\checkmark$ & \\
\hline Previous preterm delivery & 6 & $\checkmark$ & $\checkmark$ \\
\hline $\begin{array}{l}\text { Previous low } \\
\text { birthweight infant }\end{array}$ & 5 & $\checkmark$ & $\checkmark$ \\
\hline Previous GH & 1 & & $\checkmark$ \\
\hline Previous PPROM & 0 & & $\checkmark$ \\
\hline Previous GDM & 3 & & $\checkmark$ \\
\hline Previous Caesarean section & 6 & $\checkmark$ & $\checkmark$ \\
\hline $\begin{array}{l}\text { Previous postpartum } \\
\text { depression }\end{array}$ & 3 & & \\
\hline Date of last pregnancy & 0 & $\checkmark$ & \\
\hline Date of last delivery & 1 & $\checkmark$ & \\
\hline
\end{tabular}

GDM: gestational diabetes mellitus; GH: gestational hypertension; PPROM: preterm pre-labour rupture of membranes.

*NSAPD, PEIRCP, and BCPHP include data from $\mathrm{CIHI}$ for ICD codes which report on disease in the following systems: pulmonary, heart, renal, endocrine, and gastrointestinal, in addition to blood dyscrasias, neurological illness, neoplasms, and psychiatric illness. 
Table 4. Current pregnancy

\begin{tabular}{|c|c|c|c|}
\hline Variables & $\begin{array}{l}\text { PHPs that } \\
\text { collect the } \\
\text { information } \\
\quad(\mathrm{N}=6)\end{array}$ & CMDS & CPN \\
\hline \multicolumn{4}{|l|}{ Prenatal care } \\
\hline Date of first visit & 5 & $\checkmark$ & \\
\hline No. visits in pregnancy & 2 & & $\checkmark$ \\
\hline $\begin{array}{l}\text { Attendance at } \\
\text { classes/education }\end{array}$ & 4 & $\checkmark$ & \\
\hline Antenatal care provider & 4 & $\checkmark$ & \\
\hline Type* & 3 & $\checkmark$ & \\
\hline Reproductive assistance & 3 & & \\
\hline Expected date of confinement & 6 & $\checkmark$ & $\checkmark$ \\
\hline According to LMP & 4 & $\checkmark$ & \\
\hline According to ultrasound & 1 & & $\checkmark$ \\
\hline $\begin{array}{l}\text { Details of first trimester } \\
\text { ultrasound } \dagger\end{array}$ & 1 & & \\
\hline Multiple pregnancy & 6 & $\checkmark$ & $\checkmark$ \\
\hline Type of twins & 2 & & $\checkmark$ \\
\hline \multicolumn{4}{|l|}{ Prenatal diagnosis } \\
\hline Maternal serum screening & 4 & & $\checkmark$ \\
\hline Nuchal translucency & 2 & & \\
\hline Amniocentesis & 3 & & $\checkmark$ \\
\hline Chorionic villous sampling & 3 & & $\checkmark$ \\
\hline $\begin{array}{l}\text { Uterine artery Doppler } \\
\text { velocimetry }\end{array}$ & 1 & & $\checkmark$ \\
\hline \multicolumn{4}{|l|}{ Routine prenatals } \\
\hline Rubella immune & 2 & & $\checkmark$ \\
\hline Blood type & 2 & & $\checkmark$ \\
\hline Rh type & 1 & & \\
\hline $\begin{array}{l}\text { Third trimester maternal } \\
\text { hemoglobin }\end{array}$ & 2 & & \\
\hline Maternal "antibody conditions" $\ddagger$ & 3 & & \\
\hline \multicolumn{4}{|l|}{ Lifestyle§ } \\
\hline Weight gain in pregnancy\| & 5 & $\checkmark$ & $\checkmark$ \\
\hline Smoking & 6 & $\checkmark$ & $\checkmark$ \\
\hline Alcohol in pregnancy & 6 & $\checkmark$ & $\checkmark$ \\
\hline Illicit drug use & 6 & $\checkmark$ & $\checkmark$ \\
\hline \multicolumn{4}{|l|}{ LMP: last menstrual period. } \\
\hline \multicolumn{4}{|c|}{$\begin{array}{l}\text { *Includes family physician, midwife, nurse practitioner, registered nurse, } \\
\text { obstetrician, other, or none. }\end{array}$} \\
\hline \multicolumn{4}{|c|}{$\begin{array}{l}\text { †NSAPD reports on crown/rump length or biparietal diameter, head } \\
\text { circumference, abdominal circumference, and femur length. }\end{array}$} \\
\hline \multicolumn{4}{|c|}{$\begin{array}{l}\text { ‡These are reported only by NSAPD, and comprise a mixture of } \\
\text { allo-antibodies (to many red blood cell antigens including Rh and "PL-A1 } \\
\text { Platelet antigen negative"), auto-antibodies (ANA, anti-DNA, anti-SSA, and } \\
\text { anti-SSB), and thrombophilias (i.e., Factor V Leiden mutation, anticardiolipin, } \\
\text { lupus anticoagulant). }\end{array}$} \\
\hline \multicolumn{4}{|c|}{$\S$ Defined as non-heritable factors that may affect pregnancy. } \\
\hline $\begin{array}{l}\text { ॥Calculated from pre-pregnancy weight an } \\
\text { admission weight. }\end{array}$ & either pre-deliv & ery weig & \\
\hline
\end{tabular}

the CMDS, however this is rarely collected by CPN. Fewer PHPs (BCPHP and PEIRCP) collect Rh immunoglobulin (given antenatally or postpartum).

Table 5 (maternal complications and interventions) shows that few interventions other than maternal transport, blood transfusion, and corticosteroids are collected by the PHPs consistent with the CMDS. These interventions are the focus of CPN data collection, which focuses on a high-risk population as opposed to normal pregnancies. For example, while antibiotic use is collected by three PHPs and $\mathrm{CPN}$, the PHPs document only whether or not antibiotics were given antepartum, intrapartum, or postpartum; they do not collect type or dosing, all of which are captured by CPN. Also, while $\mathrm{MgSO}_{4}$ is collected by $\mathrm{CPN}$ in detail (type, route, indication, timing, and date), NSAPD and PEIRCP capture these data only when $\mathrm{MgSO}_{4}$ is used as a generic antihypertensive or anticonvulsant, or to stop preterm labour.

While all PHPs, the CMDS, and CPN collect use of corticosteroids, they all capture it slightly differently. The PHPs collect yes/no for corticosteroids. PEIRCP, NSAPD, Niday, MDS, and CPN also identify whether the course was complete or partial. Some PHPs collect type of corticosteroid; NSAPD and PEIRCP collect dexamethasone or betamethasone, while CPN collects all types. The CMDS and CPN also collect timing, time of first dose, and whether administration was antepartum, intrapartum, or postpartum. In addition, CPN collects indication for drug initiation and route of administration. Most PHPs gather information on gestational hypertension, gestational diabetes mellitus, antepartum hemorrhage, group B streptococcus, chorioamnionitis, hepatitis B, HIV, and urinary tract infections in the current pregnancy.

Table 6 (fetal complications and interventions) demonstrates that half of the PHPs collect basic fetal complications, none of which are proposed in the CMDS. These complications and interventions are the focus of CPN data collection.

Table 7 (labour and delivery) shows that basic variables are well-documented by all PHPs, although details such as induction of labour and delivery modes may differ.

Neonatal data collected are listed in Table 8. All programs collect neonatal mortality and major morbidities.

\section{DISCUSSION}

The current landscape of Canadian provincial perinatal data collection covers a wide variety of information; this basic surveillance allows for sufficient information to oversee trends in birth outcomes and in interventions. The factors that are collected most frequently by provincial PHPs are 
Table 5. Maternal interventions and complications

\begin{tabular}{|c|c|c|c|}
\hline Variables & $\begin{array}{l}\text { PHPs that } \\
\text { collect the } \\
\text { information } \\
(\mathrm{N}=6)\end{array}$ & CMDS & CPN \\
\hline
\end{tabular}

\section{General interventions}

Transport

\section{Reason for transport \\ Transferring hospital \\ Receiving hospital}

Expectant management

Outpatient surveillance program*

Blood transfusion

Drug therapy

Preconceptual folate

Preventative therapies

Corticosteroids

Antihypertensives

$\mathrm{MgSO}_{4} \dagger$

Anticonvulsants

Tocolytics

Antibiotics

Other (list)

ICU admission

Self-measurement of BP

Preterm labour $\ddagger$

Fetal fibronectin testing

\section{PPROM}

Short cervix $\ddagger$

Prolapsing membranes

Cervical surveillance

Cervical cerclage§

$$
\mathrm{GH} \ddagger
$$

HELLP syndrome

Eclampsia

Highest systolic BP

Highest diastolic BP

Worse dipstick

proteinuria antenatally

$24 \mathrm{hr}$ urine collection

proteinuria $(\mathrm{g} / \mathrm{d}$ )

Antepartum hemorrhage*

Due to placental previa

Due to placental

abruption

Due to another cause

GDM

Fever

Infections
Table 5. Continued

PHPs that

collect the

information

Variables

$(\mathrm{N}=6)$

CMDS

CPN

Obstetric

GBS infection or

colonization

Chorioamnionitis

Other\|

Hepatitis $A$

Hepatitis B

Hepatitis C

HIV

Herpes simplex

genitalis

Varicella zoster

CMV

Tuberculosis

UTI

STDI

Other (list)

Abdominal inflammation/ surgery

Coagulopathy

\section{5}

4

$\begin{array}{lll}2 & & \\ 4 & \checkmark & \checkmark \\ 3 & \checkmark & \checkmark \\ 5 & \checkmark & \checkmark \\ 3 & \checkmark & \checkmark \\ 2 & \checkmark & \checkmark \\ 2 & & \checkmark \\ 1 & & \checkmark \\ 4 & \checkmark & \checkmark \\ 3 & \checkmark & \checkmark \\ 3 & \checkmark & \end{array}$

BP: blood pressure; CMV: cytomegalovirus; GBS: group B streptococcus; GDM: gestational diabetes mellitus; GH: gestational hypertension; HELLP: hemolysis, elevated liver enzyme, low platelet syndrome; HIV: human immunodeficiency virus; ICU: intensive care unit; PPROM: preterm pre-labour rupture of membranes; STD: sexually transmitted disease; UTI: urinary tract infection

*Maternal outpatient intensive surveillance care: antepartum home care obstetrical day unit visit(s), or other (specify the type of care received, e.g., visits from home care nurse). Routine antenatal care, including outpatient clinic visits, is NOT intensive outpatient surveillance.

†Listed as an antihypertensive drug in BCPHP, therefore not distinguishable as a treatment for hypertension.

$\ddagger$ These are indications for enrolment in CPN; dates of onset and hospital admission are recorded.

§NSAPD and PEIRCP collect this as coded data from CIHI. CPN collects the following cerclage information: timing (elective or rescue, before or during admission), type (McDonald [transvaginal], Shirodkar [transvaginal], transabdominal, or unknown), and removal (when PPROM diagnosed, when APH diagnosed, with onset of labour, electively at 36 weeks, or at or after delivery).

\|Infections collected by BCPHP are postpartum wound infections, blood culture agents, and other agents. These are coded, so may not necessarily be coded as a standard. (Testing for hepatitis B, HIV, and UTIs is standard with BCPHP).

TChlamydia, gonorrhea, syphilis, bacterial vaginosis, human papillomavirus. 
Table 6. Fetal complications and interventions

\begin{tabular}{|c|c|c|c|}
\hline Variables & $\begin{array}{l}\text { PHPs that } \\
\text { collect the } \\
\text { information } \\
(\mathrm{N}=6)\end{array}$ & CMDS & CPN \\
\hline IUGR $^{*}$ & 3 & & $\checkmark$ \\
\hline Antenatal surveillance $†$ & 4 & & $\checkmark$ \\
\hline Polyhydramnios & 4 & & $\checkmark$ \\
\hline Amnioreduction & 2 & & $\checkmark$ \\
\hline Oligohydramnios & 4 & & $\checkmark$ \\
\hline Amnioinfusion & 3 & & $\checkmark$ \\
\hline Other procedures $\ddagger$ & 3 & & $\checkmark$ \\
\hline
\end{tabular}

IUGR: intrauterine fetal growth restriction

*These are indications for enrolment in CPN; dates of onset and hospital admission are recorded.

tIncludes one or more of cardiotocography, amniotic fluid volume, biophysical profile, umbilical artery Doppler velocimetry, middle cerebral artery Doppler, ultrasonographic estimated fetal weight, and fetal lung volume (with PPROM) by ultrasound or MRI.

łIncludes one or more of amnion septostomy, bladder shunt, cord occlusion, intrauterine transfusion, laser surgery, multi-fetal reduction, pleuroamnio shunt, open fetal surgery, fetal blood transfusion, fetal drainage, fetal stent placement, cordocentesis.

population-based data: demographics (both maternal and neonatal, including personal identifiers), past obstetrical history, maternal lifestyle, labour and delivery, and basic neonatal outcomes.

Ethnicity (Table 2) is documented by only two PHPs and CPN (non-mandatory). This de-emphasis reflects varying perceptions about ethnicity and continued debate about its significance with respect to health. Today, ethnicity is commonly defined as self-identification with a culture (if any) of which individuals consider themselves to be a part. As such, ethnicity becomes subjective, making it almost impossible to relate ethnicity data as collected to specific genetic risks that correlate with ethnicity defined by genetic polymorphisms. As our population becomes more ethnically heterogeneous, ethnicity becomes less of a discernible predictor of health status. Rather, the cultural implications of ethnicity become more significant. ${ }^{10}$ Even if it were advantageous to use ethnicity as an indicator, large databases do not have the facility to collect this information, because of the complexities noted above. Although the paucity of ethnicity data in the various Canadian PHP databases appears justified, we do need variables that denote socioeconomic status and lifestyle, such as beliefs, diet, and support.

Including personal identifiers in databases allows for confirmation of data, updates, corrections or improvements, and perhaps definitive linkage to other provincial or national databases. In this analysis, all of the PHPs, the CMDS, and
CPN allow for this. On the other hand, a patient's health number or name allows for linkages to other identifiers, which could lead to other information and networks such as laboratory results at other facilities or other provincial or national networks. In this case, only PEIRCP, NLPPP, NSAPD, BCPHP, CMDS, and CPN collect this information.

Because it includes only the direct variables collected by the programs, the current study is limited by not accounting for the potential linkages that databases could have with other resources for additional information using personal identifiers. For example, PHPs could potentially link a patient to other databases to receive laboratory results, prescriptions filled by pregnant women, or details of newborn screening and immunization. This could also allow for longitudinal linkages that would connect to educational or environmental databases for long-term outcomes.

Our analysis shows that the CPN database was needed to collect detailed information on interventions. Within most PHPs there are insufficient data with respect to obstetric (and neonatal) practices to enable the identification of practices associated with good or poor maternal or perinatal outcomes. For example, PHP data, if more were collected, could be used to determine the optimal type of antibiotic for PPROM. Specifically, no PHPs have detailed information about outpatient surveillance programs (Table 4), while the use of $\mathrm{MgSO}_{4}$ is only specifically named in two PHPs (PEIRCP and NSAPD). This is despite the grade I-A recommendation of use of $\mathrm{MgSO}_{4}$ in the Canadian, ${ }^{11} \mathrm{US}$ (NHBPEP 2000), ${ }^{12}$ and Australian (ASSHP 2000) ${ }^{13}$ guidelines for management of the hypertensive disorders of pregnancy, and, therefore, an auditable standard for provincial, national, and international benchmarking. When databases label $\mathrm{MgSO}_{4}$ as an antihypertensive, it means that the use of an effective intervention cannot be assessed in that jurisdiction.

The variability between PHP databases is recognized by the CPPC, which proposed the CMDS as a first step towards harmonization, time and budgetary constraints allowing. While many PHPs collect similar information, many collect information in various ways (e.g., direct versus calculated parity) or have different definitions (e.g., for preterm delivery or pre-existing hypertension).

It must be recognized that no database can be all things to all people. The PHPs aim to monitor trends over time, evaluate guidelines, and identify issues that require further attention or are appropriate for epidemiological and other research. Identifying geographical clusters of risk factors for targeting health care actions is a powerful tool for effective interventions, ${ }^{14}$ as PHP population cohorts represent the general maternity population. The PHPs should also 
Table 7. Labour and delivery

\begin{tabular}{|c|c|c|c|}
\hline Variables & $\begin{array}{l}\text { PHPs that } \\
\text { collect the } \\
\text { information } \\
(\mathrm{N}=6)\end{array}$ & CMDS & CPN \\
\hline Length of stay* & 5 & & $\checkmark$ \\
\hline Admission number & 5 & & \\
\hline \multicolumn{4}{|l|}{ Induction of labour } \\
\hline Indication & 6 & & $\checkmark$ \\
\hline Method (list) & 6 & $\checkmark$ & $\checkmark$ \\
\hline $\mathrm{N}$ induction attempts & 2 & & \\
\hline Labour augmentation & 6 & $\checkmark$ & $\checkmark$ \\
\hline Method (list) & 4 & & \\
\hline \multicolumn{4}{|l|}{ ROM } \\
\hline Spontaneous/artificial & 3 & $\checkmark$ & \\
\hline Date/time & 5 & $\checkmark$ & $\checkmark$ \\
\hline Fetal presentation & 6 & $\checkmark$ & $\checkmark$ \\
\hline \multicolumn{4}{|l|}{1 st stage of labour } \\
\hline Duration of 1 st stage & 5 & & $\checkmark$ \\
\hline Rate of dilatation for 1 st stage $\dagger$ & 2 & & \\
\hline General tract and perineal traumał & 5 & $\checkmark$ & \\
\hline 2nd stage of labour duration & 6 & & $\checkmark$ \\
\hline 3rd stage of labour duration & 4 & & \\
\hline \multicolumn{4}{|l|}{ Fetal surveillance in labour§ } \\
\hline Scalp pH & 2 & & \\
\hline Meconium staining & 4 & $\checkmark$ & \\
\hline Shoulder dystocia & 3 & $\checkmark$ & \\
\hline Analgesia/anaesthesia & 6 & $\checkmark$ & $\checkmark$ \\
\hline \multicolumn{4}{|l|}{ Type } \\
\hline None & 6 & $\checkmark$ & $\checkmark$ \\
\hline $\begin{array}{l}\text { Narcotics (includes PCA } \\
\text { pump) }\end{array}$ & 5 & $\checkmark$ & $\checkmark$ \\
\hline Nitrous oxide & 3 & $\checkmark$ & $\checkmark$ \\
\hline $\begin{array}{l}\text { Local anaesthetic } \\
\text { (e.g., pudendal block) }\end{array}$ & 5 & $\checkmark$ & $\checkmark$ \\
\hline $\begin{array}{l}\text { Regional (epidural, spinal, } \\
\text { or spinal-epidural) }\end{array}$ & 5 & $\checkmark$ & $\checkmark$ \\
\hline General & 5 & $\checkmark$ & $\checkmark$ \\
\hline Other $\|$ & 6 & $\checkmark$ & $\checkmark$ \\
\hline Unknown & 2 & $\checkmark$ & $\checkmark$ \\
\hline
\end{tabular}

Table 7. Continued

PHPs that collect the information

Variables $(\mathrm{N}=6)$

CMDS CPN

Maternal complications of 3 anaesthesia

Mode of delivery

Vaginal

Forceps/vacuum

VBAC

Caesarean section

Indications for

Caesarean section

Type

Cervical dilatation at Caesarean section

Intrapartum blood loss

3

Type of caregiver who deliveredף

Mother's discharge disposition (home, transfer, unknown) alive/dead

PCA: patient controlled analgesia; VBAC: vaginal birth after Caesarean section.

${ }^{*}$ Calculated by day of discharge - day of admission or date and time of discharge - date and time of birth. This refers to delivery admission, except for CPN which also refers to other antepartum admissions. NSAPD and

NLPPP also have the capability to collect antepartum admissions prior to delivery admissions.

†Rate $=$ (cervical full dilatation - dilatation at admission) / (time at full dilatation - time at admission)

‡Episiotomy, laceration, or cervical tear.

§External/internal and intermittent/continuous FHR monitoring, auscultation of FHR, scalp pH.

|lncludes non-pharmacological methods such as transcutaneous nerve stimulation, hypnosis, acupuncture, aromatherapy, New Age, and deep breathing or meditation techniques.

IGP, obstetrician, RN, midwife, nurse practitioner, resident, other MD, paramedic, at home, surgeon, or no attendant. 
Table 8. Perinatal outcomes

\begin{tabular}{|c|c|c|c|}
\hline Variables & $\begin{array}{l}\text { PHPs that } \\
\text { collect the } \\
\text { information } \\
(\mathrm{N}=6)\end{array}$ & CMDS & CPN \\
\hline \multicolumn{4}{|l|}{ Outcome } \\
\hline $\begin{array}{l}\text { Termination of } \\
\text { pregnancy }\end{array}$ & 0 & $\checkmark$ & \\
\hline Stillbirth & 6 & $\checkmark$ & $\checkmark$ \\
\hline Live birth & 6 & $\checkmark$ & $\checkmark$ \\
\hline Neonatal death & 6 & $\checkmark$ & $\checkmark$ \\
\hline \multicolumn{4}{|l|}{ For neonatal death } \\
\hline Age at death* & 3 & $\checkmark$ & $\checkmark$ \\
\hline Autopsy & 3 & $\checkmark$ & \\
\hline Cause & 3 & $\checkmark$ & $\checkmark$ \\
\hline Gestational age & 6 & $\checkmark$ & $\checkmark$ \\
\hline \multicolumn{4}{|l|}{ Neonatal } \\
\hline Meconium aspiration & 3 & $\checkmark$ & \\
\hline Fracture & 3 & $\checkmark$ & \\
\hline \multicolumn{4}{|l|}{ Cord blood gases } \\
\hline $\mathrm{pH}$ & 5 & $\checkmark$ & $\checkmark$ \\
\hline Base excess & 5 & $\checkmark$ & $\checkmark$ \\
\hline $\mathrm{pCO}_{2}$ & 2 & & $\checkmark$ \\
\hline \multicolumn{4}{|l|}{ Apgar scores } \\
\hline 1 minute & 6 & $\checkmark$ & \\
\hline 5 minutes & 6 & $\checkmark$ & \\
\hline 10 minutes & 4 & $\checkmark$ & \\
\hline Vitamin $\mathrm{K}$ administered & 2 & & \\
\hline Resuscitation/ventilation & 6 & $\checkmark$ & $\checkmark$ \\
\hline Admission to hospital & 3 & & \\
\hline Gender & 5 & $\checkmark$ & $\checkmark$ \\
\hline Rh type & 1 & & \\
\hline Blood group & 1 & & \\
\hline \multicolumn{4}{|l|}{$\begin{array}{l}\text { Anthropomorphic } \\
\text { measurements }\end{array}$} \\
\hline Birthweight & 5 & $\checkmark$ & $\checkmark$ \\
\hline Length & 4 & $\checkmark$ & \\
\hline Head circumference & 6 & $\checkmark$ & \\
\hline Major Congenital anomaly† & 4 & $\checkmark$ & $\checkmark$ \\
\hline Chromosomal abnormality & 3 & $\checkmark$ & \\
\hline Neonatologist & 2 & & \\
\hline Admission to NICU & 6 & & $\checkmark$ \\
\hline TRIPS score & 1 & & \\
\hline SNAP II score & 1 & & \\
\hline Length of stay (days) $\ddagger$ & 5 & & $\checkmark$ \\
\hline $\begin{array}{l}\text { Mechanical ventilation } \\
\& \text { mode }\end{array}$ & 5 & & $\checkmark$ \\
\hline $\begin{array}{l}\text { Total parenteral } \\
\text { nutrition }\end{array}$ & 3 & & $\checkmark$ \\
\hline Transfusion & 2 & & $\checkmark$ \\
\hline $\begin{array}{l}\text { Complications of } \\
\text { prematurity§ }\end{array}$ & 4 & $\checkmark$ & $\checkmark$ \\
\hline
\end{tabular}

Table 8. Continued

\begin{tabular}{|c|c|c|c|}
\hline Variables & $\begin{array}{l}\text { PHPs that } \\
\text { collect the } \\
\text { information } \\
(\mathrm{N}=6)\end{array}$ & CMDS & CPN \\
\hline Procedures $\|$ & 3 & & $\checkmark$ \\
\hline $\begin{array}{l}\text { Complications of } \\
\text { procedures }\end{array}$ & 3 & & \\
\hline $\begin{array}{l}\text { Central venous } \\
\text { catheter(s) }\end{array}$ & 1 & & $\checkmark$ \\
\hline Infant medications & 2 & & $\checkmark$ \\
\hline Other neonatal complications & 4 & $\checkmark$ & $\checkmark$ \\
\hline \multicolumn{4}{|l|}{ Infant feeding } \\
\hline $\begin{array}{l}\text { Mother's intention to } \\
\text { breastfeed }\end{array}$ & 5 & & \\
\hline Early breast contact & 2 & & \\
\hline Infant feeding (type) & 5 & $\checkmark$ & \\
\hline Reason for substitute & 2 & & \\
\hline Jaundice/phototherapy & 3 & & \\
\hline Newborn screening \& type & 1 & & \\
\hline Immunizations & 1 & & \\
\hline \multicolumn{4}{|l|}{ Discharge disposition } \\
\hline Details of transfer\# & 4 & $\checkmark$ & $\checkmark$ \\
\hline Needed home oxygen & 2 & & \\
\hline Neonatal Follow-up clinic & 1 & & \\
\hline
\end{tabular}

NICU: neonatal intensive care unit; SNAP: score for neonatal acute physiology; TRIPS: temperatory, respiratory status, systolic BP, response to noxious stimuli.

${ }^{*}$ Can be calculated by date of death-date of birth.

†Specific list from Niday and CMD includes: anencephaly, spina bifida, meningocele, myelomeningocele, hydrocephaly, cleft lip, cleft palate, Down syndrome, neural tube defect, defects of CNS, GI, renal, respiratory, cardiovascular, or musculoskeletal systems, and other. BCPHP, PEIRCP, and NSAPD code others, while APHP records Y/N. CPN has a field to enter the data.

‡Calculated from discharge date - admission date.

§BPD (bronchopulmonary dysplasia) or CLD (chronic lung disease), ROP (retinopathy of prematurity), severe IVH (intraventricular hemorrhage), NEC (necrotizing enterocolitis), HIE (hypoxic-ischemic encephalopathy)/ convulsions/seizures, or neonatal sepsis.

\|Laparotomy, thoracotomy, craniotomy, ECMO (extracorporeal membrane oxygenation)

TIncludes fetal malnutrition/soft tissue wasting, patent ductus arteriosus, pulmonary hypertension of newborn, respiratory distress syndrome, birth asphyxia sequelae, and neoplasms.

\#Includes at least two of the following; date, time, destination, and reason for transfer. 
ensure that there is equal emphasis on determinants of health and on interventions, such as the grade I-A recommendations outlined by clinical practice guidelines. The PHPs would then be in a position to audit and validate recommendations in larger jurisdictions. Examples of grade I-A recommendations that PHPs cannot report on are the CMDS's lack of prenatal diagnosis or routine prenatal bloodwork. According to Summers et al., all pregnant women in Canada should be offered prenatal screening and second trimester ultrasound for dating growth and anomalies. ${ }^{15}$ Similarly, Keenan-Lindsay and Yudin have advised that all women should be offered HIV screening at their first prenatal visit (I-A) ${ }^{16}$; however, APHP and NLPPP do not collect this information. Moreover, the use of $\mathrm{MgSO}_{4}$ as prophylaxis against, and treatment of, eclampsia in women with severe preeclampsia (I-A ${ }^{17}$ ) is only collected by NSAPD and PEIRCP (as a yes/no question). Every PHP collects information about antenatal corticosteroid use.

The challenge begins now that researchers and PHPs have started to become interested in interprovincial and national comparisons, especially with the electronic health record on the horizon. While the shift to electronic health records will be the main stimulus driving standardization of data definitions, PHPs will influence what data fields are collected. Because most PHPs influence, revise, and create the antenatal, perinatal, and labour and delivery forms, electronic vendors will be seeking advice and expertise from the PHPs as to which data to include in electronic health records.

\section{CONCLUSION}

Variations in language across perinatal databases are a great challenge that all local, provincial, and national organizations will eventually have to overcome. The future direction is towards a standardized language on which all databases and the electronic health record will be based. Standardized definitions will allow for data sharing supplemented by specific, focused data collection. The CPPC, through the CMDS, has started to tackle this issue. Converging with the new language of the electronic health record, SNOMED CT (Systematized Nomenclature of Medicine-Clinical Terms) will be the next step.

\section{ACKNOWLEDGEMENTS}

Many thanks to the PHP and CMDS representatives and coordinators for their time, effort, and contributions to this analysis: Rebecca Attenborough, Reproductive Care
Program of Nova Scotia; Irene Gagnon, Reproductive Care Program of Nova Scotia; Diane Boswall, PEI Reproductive Care Program; Jim Bottomley, Ontario Perinatal Surveillance System; Phil A. Murphy, Newfoundland and Labrador Provincial Perinatal Program; Tammie Bunnah, Alberta Perinatal Health Program.

\section{REFERENCES}

1. Health Canada. Canadian Perinatal Health Report 2003. Ottawa: Minister of Public Works and Government Services Canada, 2003. Available at http://www.phac-aspc.gc.ca/publicat/cphr-rspc03/pdf/cphr-rspc03_e.pdf. Accessed December 15, 2008.

2. Canadian Perinatal Programs Coalition (CPPC). Canadian Perinatal Programs Coalition (CPPC) Terms of Reference. 2004. Available at http://rcp.nshealth.ca/rcp_3461.html. Accessed December 15, 2008.

3. Canadian Perinatal Network. 2006. Available at: http://www.cpn-rpc.org. Accessed December 15, 2008.

4. Nova Scotia Atlee Perinatal Database. 2008. http://rcp.nshealth.ca/ rcp_3347.html. Accessed December 15, 2008.

5. PEI Reproductive Care Program. 2005. Available at: http://www.phac-aspc.gc.ca/ ccasn-rcsac/dss/pei-eng.php. Accessed December 15, 2008.

6. Newfoundland and Labrador Provincial Perinatal Program. 2008. http://www.nlppp.ca/perinataldatabase.htm. Accessed December 15, 2008

7. Niday Perinatal Database. 2008. Available at: https://www.nidaydatabase.com/info/guide_definitions.shtml. Accessed December 15, 2008.

8. Alberta Perinatal Health Program. 2007. Available at: http://www.aphp.ca. Accessed December 15, 2008.

9. BC Perinatal Health Program. 2008. Available at: http://www.bcphp.ca. Accessed December 15, 2008.

10. Callister P, Didham R, Potter D, Blakely T. Measuring ethnicity in New Zealand: developing tools for health outcomes analysis. Ethn Health 2007;12(4):299-320.

11. Magee LA, Helewa M, Moutquin JM, von Dadelszen P, Cardew S, Côté $\mathrm{AM}$, et al. Diagnosis, evaluation, and management of the hypertensive disorders of pregnancy. J Obstet Gynaecol Can 2008;30(3 Suppl):S1-S48.

12. Report of the National High Blood Pressure Education Program Working Group on High Blood Pressure in Pregnancy. Am J Obstet Gynecol 2000;183:S1-S22.

13. Brown MA, Hague WM, Higgins J, Lowe S, McCowan L, Oats J, et al. The detection, investigation and management of hypertension in pregnancy: Executive summary. Aust N Z J Obstet Gynaecol 2000;40:133-8.

14. Clark RC, DeMarco ML. Development of an information management system using a strategic planning process. Top Health Inf Manage 2001;22(2):44-51.

15. Summers AM, Langlois S, Wyatt P, Wilson RD. Prenatal screening for fetal aneuploidy. J Obstet Gynaecol Can 2007;29(2):146-79.

16. Keenan-Lindsay L, Yudin MH, Boucher M, Cohen HR, Gruslin A, MacKinnon, CJ, et al. HIV screening in pregnancy. J Obstet Gynaecol Can 2006;28(12):1103-12.

17. Crane J, Armson A, Brunner M, De La Ronde S, Farine D, Keenan-Lindsay L, et al. Antenatal corticosteroid therapy for fetal maturation. J Obstet Gynaecol Can 2003;25(1):45-5. 


\section{APPENDIX: CPN Members}

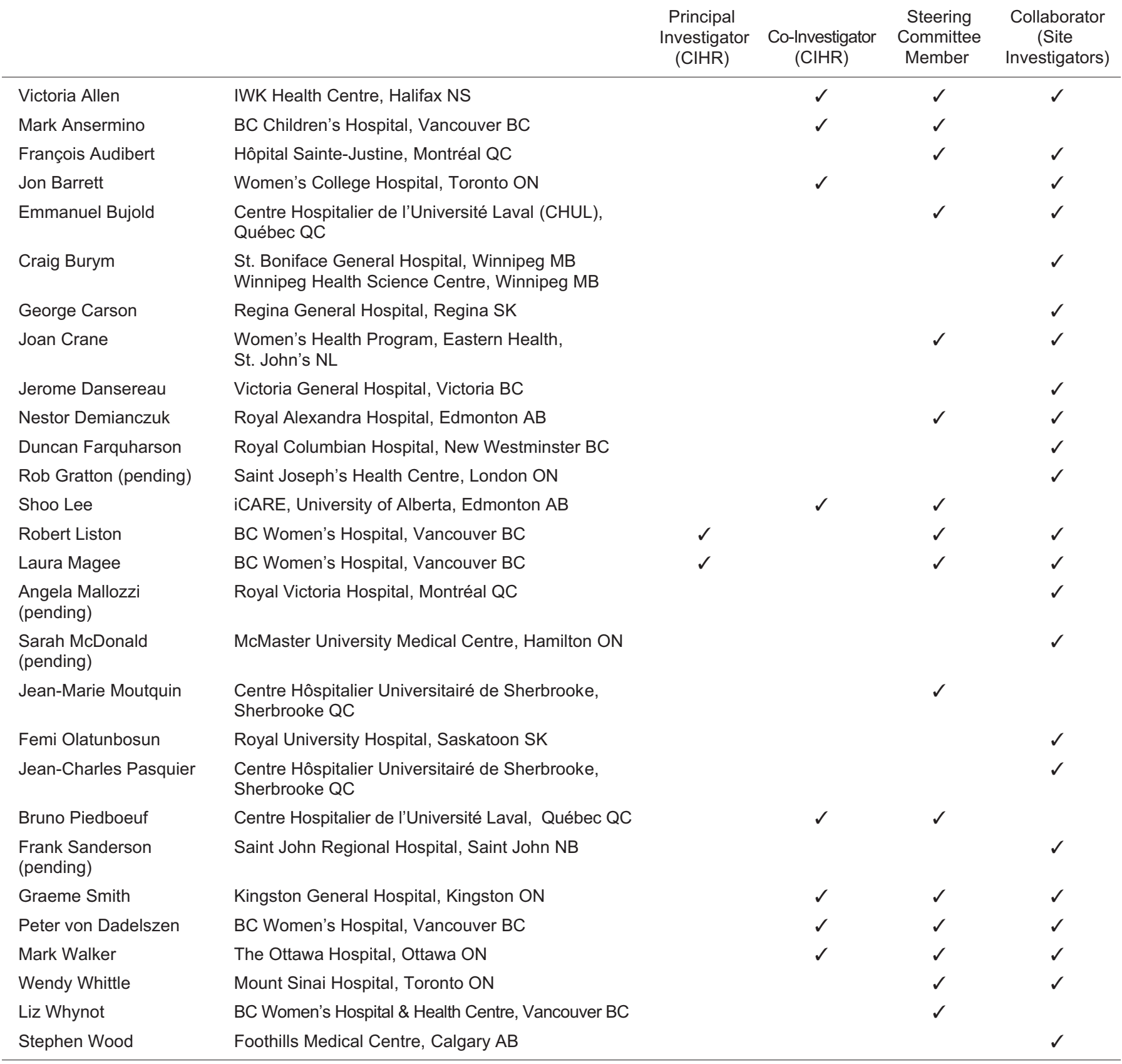

